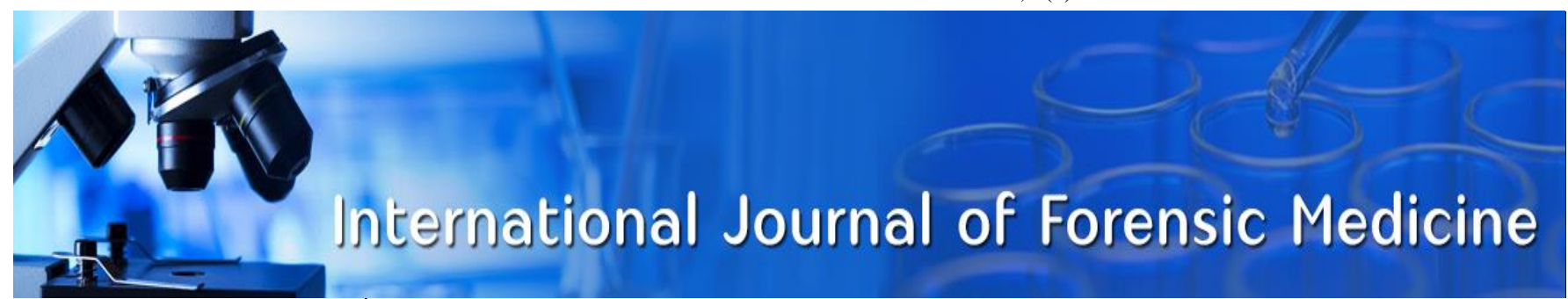

E-ISSN: 2707-4455

P-ISSN: 2707-4447

www.forensicpaper.com/

IJFM 2019; 1(1): 04-06

Received: 05-11-2019

Accepted: 08-12-2019

\section{Dr. Anmol Upreti}

Department of Forensic

Medicine, Dhulikhel Hospital

Department of Forensic

Medicine, Patan, Nepal
Corresponding Author: Dr. Anmol Upreti Department of Forensic Medicine, Dhulikhel Hospital Department of Forensic Medicine, Patan, Nepal

\title{
Determination of age from fusion of skull vault sutures
}

\section{Dr. Anmol Upreti}

DOI: https://doi.org/10.33545/27074447.2019.v1.i1a.2

\begin{abstract}
Background: Cranial suture closure has long been recognized as a character of human development related to aging. For this reason, it has been utilized for various forensic and archaeological studies to determine the age of an unidentified/or skeletonized individuals. Various cadaveric studies have established the role of lambdoid suture in age estimation, but not routinely practiced. Age estimation is an integral part of the biological profile employed by forensic anthropologists in order to assist in achieving an identification of an unknown deceased individual. The main objective of this article is to determine the pattern of cranial vault suture closure in relation to age.

Material and methods: Total number of 90 subjects, 25 years and beyond were included in the study, and divided into four groups with an age interval of 10 years. Each individual was subjected to radiological examination of the skull with a view to- study the Sagittal, Coronal and Lambdoid sutures, a special view was evolved by trial in order to get all the basic three sutures in one film. Ectocranial and endocranial closure pattern were studied.

Result: A significant difference was observed between the age group and suture closure. Coronal suture was the first to fuse followed by sagittal suture. Lambdoid suture. Endocranially, starts fusing at the age of 25-30 yrs. Closure was found earlier in females compared to males.

Conclusion: Suture obliteration occurs earlier on endocranial surface. Based on endocranial suture fusion, Coronal suture was first to close followed by sagittal suture, lambdoid suture sequentially.
\end{abstract}

Keywords: Suture; cranial, lambdoid, suture closure, reverse panoramic radiograph, age estimation

\section{Introduction}

Determination of age is a common medico legal problem both in the living and dead. An opinion with reasonable accuracy can be given up to 25 years of age. Beyond this, age determination is associated with high percentage of deviation ${ }^{[1]}$. Changes in the hair, eyes, odontological changes as based on Gustafson's law and Closure of Cranial sutures are some of the data helpful in the middle age group and upwards ${ }^{[2]}$. The present study' has been undertaken to find out the reliability of closure of Cranial Sutures as one of the data in determination of age in the living.

Age estimation is an integral part of the biological profile employed by forensic anthropologists in order to assist in achieving an identification of an unknown deceased individual. Its estimation is of paramount importance and requires special attention in cases where bodies are found in decomposed, mutilated state or only fragmentary remains are discovered. After 25 years of age, other scientific methods like tooth microscopy, Gustafson's method (applicable to dead persons only), study of union of parts of sternum, lipping of joints and closure of cranial sutures are considered for age estimation of the individual ${ }^{[3]}$. The oldest and most controversial age indicator is cranial suture closure. Cranial sutures generally fuse with increasing age, although there is considerable variability in closure rates and patterns.

Cranial sutures have been of great interest for age estimation, as its closure varies according to age. Lambdoid suture of all the cranial suture has been suggested to be the last vault suture to attain closure at around 42 to 50 years and has its forensic importance. Anatomically, lambdoid suture has been divided into three different positional parts from medial to lateral into pars lambdica, pars intermedia, and pars asterica ${ }^{[4]}$.

Various autopsy and or cadaveric studies have been done on cranial suture for age estimation but, studies specifically on lambdoid sutures in mortals using radiographs for age estimation are very sparse. The method of determining age by cranial suture closure has always been more generally used, but because the cranium is frequently the best preserved portion of the 
recovered skeleton ${ }^{[5]}$. Cranial sutures generally fuse with increasing age, although there is considerable variability in closure rates and patterns. The idea that cranial bones fuse progressively with age has been in existence since at least the 16th century. Since the 16th century this method of age assessment has been studied in various populations with several methods introduced to produce the most accurate results ${ }^{[6]}$.

In more recent decades, many studies discussing the lack of accuracy and reliability of various methods have been published ${ }^{[7]}$. To obtain more information on its usefulness, we undertook a study to find out the pattern of cranial vault suture closure during 3rd to 5th decades, to detect bilateral and dimorphic variations and to specify any relationship between progressions of union of cranial suture with age of an individual.

\section{Material and methods}

Ninety five individuals of different age groups where taken up for the study. This prospective and unicentric study was conducted on 95 randomly selected healthy subjects, visiting the department of Oral Medicine and Radiology. Subjects were divided into four groups, with an age interval of 10 years: group A (21-30 years); group B (31-40 years); group C (41-50 years); and group D (50 years and above). The study was approved by the Institutional Human Ethics Committee and written informed consent was obtained from each subject after explaining the purpose and method of the study.

After confirmation of age of the subjects from birth certificate, driving license, passport, aadhar card, a proper case history was recorded on a prescribed performa. However, individuals with history of skull surgery, trauma, or developmental anomaly related to skull, history or clinical characteristics of endocrine disturbances, nutritional diseases or hereditary facial asymmetries and without age proof, were excluded.

Each individual was subjected to radiological examination of the skull with a view to study the Sagittal, Coronal and Lambdoid sutures, a special view was evolved by trial in order to get all the basic three sutures in one film. The patient was positioned for the true lateral view, but the tube head was kept at 30 degree towards. 32 feet and 15 degree towards nose, keeping the distance of the tube head at 36 inches. The following exposure factors were utilized using the grid $20 \mathrm{MA} s$ and $80 \mathrm{KVp}$.

Scale for closure: Acsadi Nemeskeri complex method $0=$ Open. There is still little space left between edges of adjoining bones.

1 = Incipient closure. Clearly visible as a continuous often zigzagging line.

$2=$ Closure in process. Line thinner, less zigzags, interrupted by complete Closure

3 = Advanced closure. Only pits indicate where the suture is located (almost complete closure)

$4=$ Closed. Even location cannot be recognised.

\section{Result}

As endocranial suture fusion is stable, speedy, uniform and complete, it was taken into consideration for age estimation. Sagittal suture starts fusing in between 25-30 yrs and almost Complete closure of Sagittal suture occurs at the age of 60 to 65 yrs. Coronal suture starts fusing in between 25-30 yrs and almost Complete closure of coronal suture occurs at the age of 55 to 60 yrs. Lambdoid suture starts fusing in between 25-30 yrs and almost complete closure of lambdoid suture occurs at the age of 65 to 70 yrs.

Findings of the sagittal suture on endocranial side showed that S2 closure started early followed by $\mathrm{S} 1$ and $\mathrm{S} 3$ respectively. Once started, S1 fused fastest and S3 the slowest. Ectocranially, suture closure followed the same pattern as that endocranially. While S1 fused fastest, S2 fused slowest as against S3 endocranially.

The examination of the coronal suture on endocranial side showed that lower coronal suture closure started early compared to upper half. Once commenced, the lower part appears to fuse much faster compared to upper part. Ectocranially, the closure and fusion followed the pattern as observed endocranially. There was no significant difference in time of closure between right and left side in either sex. Lambdoid suture on endocranial side showed that upper lambdoid suture closure started early compared to lower part; and once commenced, the upper part appears to fuse much faster than the lower part. Ectocranially, the pattern was similar to endocranial fusion. There was no significant difference between right and left side.

Table 1: Sagittal suture

\begin{tabular}{|l|c|c|c|c|}
\hline & S1 & S2 & S3 & S4 \\
\hline Ectocranially (Age group in yrs) & $60-65$ & $60-65$ & $60-65$ & $45-50$ \\
\hline Endocranially (Age group in yrs) & $60-65$ & $45-50$ & $40-45$ & $25-30$ \\
\hline
\end{tabular}

Table 2: Lambdoid suture

\begin{tabular}{|c|c|c|c|}
\hline & L1 & L2 & L3 \\
\hline Ectocranially (Age group in yrs) & $50-55$ & $60-65$ & $60-65$ \\
\hline Endocranially (Age group in yrs) & $40-45$ & $50-55$ & $65-70$ \\
\hline
\end{tabular}

Table 3: Corooid suture

\begin{tabular}{|l|c|c|c|}
\hline & C1 & C2 & C3 \\
\hline Ectocranially (Age group in yrs) & $60-65$ & $>70$ & $>70$ \\
\hline Endocranially (Age group in yrs) & $55-60$ & $50-55$ & $35-40$ \\
\hline
\end{tabular}

\section{Discussion}

Cranial sutures are line of junction of skull bones separated by a zone of connective tissue (sutural ligament), and are known to attain closure during the life time of an individual. The skull vault comprises mainly of three major sutures i.e., coronal, sagittal, and lambdoidal sutures (1). Sutures appear simple and straight in younger age groups but as the age advances these acquire a more complex anatomy (developing inter digitations by process of growth).

From the present study it is clearly evident that endocranial union is a far better parameter for age determination than is the ecotocranial union as also has been established by Todd \& Lyon (1924 \& 1925) ${ }^{[9]}$ Dwight. In our present study we found that the sagittal suture, endocranially, starts fusing at the end of 25 yrs and completion is perfected at the age of $60-65 \mathrm{yrs}^{\text {in } \mathrm{I}^{\text {st }}}$ part of sagittal suture, 45-50 yrs in $\mathrm{II}^{\text {nd }}$ part of sagittal suture, 40-45 yrs in III ${ }^{\mathrm{rd}}$ part of sagittal suture and 25-30 yrs in IVth part of sagittal suture. ${ }^{8}$ This observation conforms with that reported by Todd \& Lyon (1924) ${ }^{[9]}$ and with that reported by Ulhas shetty (2006) ${ }^{[11]}$ (sagittal suture closure at the age of 60-69 years) while it is in contrast to the observation reported by Pommerol (1869) ${ }^{[12]}$, and Topinard (1885) ${ }^{[12]}$, who indicated endocranial commencement of sagittal suture at a much later age at 
about 40 years. These latter workers have reported on very few specimens so it can't be considered as authentic ${ }^{[9,10]}$.

A correct estimation of age in elderly people is essential in legal, medical, social and administrative matters i.e. to fixing of age for regularization of employment, superannuation, pension settlements, and senior citizen benefits, Retierments1 According to J.B. Mukherjee estimation of age from suture closure of skull can be given in a range of 5-10 yrs in age of 30-60 yrs, the range may even be more in higher age groups ${ }^{[13]}$. Also according to Reddy estimation of age from suture closure of skull can be given only in a range of decades ${ }^{[10]}$. In our study range has been given in range of 5 yrs.

In our present study we also found that endocranial surface closure occurs earlier than the ectocranial except in few sutures like third part of lambdoid suture endocrinally. However in these sutures sample size was very small to draw conclusion. Some workers including Singer \& Mckern and Stewart have stated unequivocally that suture closure is unreliable as a guide to the age of a skull ${ }^{[14]}$.

Present studies reveal that obliteration of the various segments of the three main sutures of the skull is so inconclusive that neither does it help in estimating the age of the deceased nor does it provide any supportive evidence in determining the age of skeletal remain.

In summary, we report that, all the three main sutures of the skull started closing earlier in females compared to males, like that seen in long bones where the metaphyses fuses earlier in females. Moreover, endocranial union is a far better parameter for age determination than the ecotocranial union.

Present study was done on small sample size. So if done on large sample more correct conclusions can be given.

\section{Conclusion}

Our analyses strengthen the view that, with techniques available at present, an assessment regarding the precise age of an individual, gauzed only on the degree of closure of the vault sutures of the skull, is a hazardous and highly unreliable procedure. We further conclude that, after certain age, suture growth is unrelated to age and is controlled by other biological factors that are poorly understood.

However, it is still important to refine the methods of quantifying these structures, in order to render the methods of quantification as unbiased as possible. Study of Cranial Sutures 'by Radiological means is helpful to some extent in determining the age in the living. The Sutures, which are helpful, are sagittal, coronoid and Lambdoid. Complete absence of closure of these sutures indicate the age to be below 30 years and complete fusion of all the three 'sutures fixes the age group' to be above 40 years.

\section{References}

1. Krogman WM. The Human Skeleton in Forensic Science. (1stedn), Springfield USA: Charles C, Thomas, 1962.

2. Meindl RS, Lovejoy CO. Ectocranial suture closure: a revised method for the determination of skeletal age at death based on the lateral-anterior sutures. Am J Phys Anthropology. 1985; 68:57-66.

3. Johnston FE. Sequence of epiphyseal union in a prehistoric Kentucky population from Indian Knoll. Hum Biol. 1961; 33:66-81.
4. Bennett KA. Craniostenosis: a review of the etiology and a report of new cases. American journal of Physical Anthropology. 1967; 21:1-9.

5. Brooks ST. Skeletal age at death: Reliability of cranial and pubic age indicators. American journal of Physical Anthropology, 1955, 13.

6. Vijay Kumar AG, Agarwal SS, Bastia BK, Shivaramu MG, Honnungar RS. Fusion of Skull Vault Sutures in Relation to Age-A Cross Sectional Postmortem Study Done in 3rd, 4th \& 5th Decades of Life. J Forensic Res. 2012; 3:173.

7. Kapadia D, Rathva A, Kubavat DM, Nagar SK. Study of sutures: anatomical variations in the fusion of sutures. Int J Recent Trends Sci Technol. 2013; 8:94-9.

8. Parikh CK. Parikh's Textbook of Medical Jurisprudence and Toxicology. 5th Ed. New Delhi: CBS Publishers and Distributors, 1990.

9. Todd TW, Lyon DW. Endocranial suture closure, its progress and age relationship: Part I adult males of the white stock. American journal of Physical Anthropology. 1924; 7:325-384.

10. Reddy KSN. Identification. In: The Essentials of Forensic Medicine and Toxicology. 29th ed. Devi KS, 2010, 72.

11. Shetty U. Macroscopic study of cranial suture closure at autopsy for estimation of age. Anil Aggrawal's Internet Journal of Forensic Medicine and Toxicology, 2009.

12. Pommerol (1869), Topinard (1885). Estimation of age from cranial suture closure: A report of its unreliability. Journal of Forensic Medicine, 1953.

13. Mukherjee JB. Identification. In: Textbook of Forensic Medicine and Toxicology.3rd ed. Karmakar RN. Academic publishers Kolkata, 2007, 156-157.ss

14. Singer R. Estimation of age from cranial suture closure: A report of its unreliability. Journal of Forensic Medicine, 1953. 